\title{
To damselfish, modeling comes naturally
}

SCIENTIFIC NAME

Stegastes partitus

TAXONOMY

PHYLUM: Chordata

CLASS: Actinopterygii

ORDER: Perciformes

FAMILY: Pomacentridae

\section{Physical description}

The bicolor damselfish is a tropical marine species that inhabits shallow coral reefs in the western Atlantic Ocean and Gulf of Mexico. Damselfish have an oval-shaped body with a two-tone coloration that varies somewhat with geography.

\section{Research résumé}

Prior to the advent of strategies that enabled scientists to create animal models for specific diseases of interest, researchers often relied on naturally occurring disease models. The bicolor damselfish nicely illustrates the role of such spontaneous models in biomedical research.

In 1983, Schmale et al. reported the occurrence of multiple Schwannomas (benign tumors of peripheral nerve sheath cells) in $5-10 \%$ of adults in certain damselfish populations near southern Florida ${ }^{1}$. The affected fish also had pigment changes and multiple neurofibromas and neurofibrosarcomas. Although peripheral nerve sheath tumors had been previously reported in various species, the observations in damselfish seemed to be the first instance of persistent, widespread tumors in a natural population. As such, Schmale et al. proposed that the bicolor damselfish could be a useful model for investigating the characteristics and pathogenesis of nerve sheath tumors.

Nerve sheath tumors, along with epidermal hyperpigmentation and iris hamartomas (or Lisch nodules), are typical symptoms of neurofibromatosis type 1 (also called von Recklinghausen disease) in humans. Schlumberger's comparison of nerve sheath tumors in goldfish and humans brought to light many similarities ${ }^{2}$, which Schmale et al. suggested could also carry over to damselfish. In both damselfish and humans with neurofibromatosis, the most common finding is hyperpigmentation. Although the damselfish does not recapitulate all features of human neurofibromatosis, Schmale et al. planned to pursue the damselfish as a neurofibromatosis model, investigating the etiology of the disease. Continued work showed that damselfish neurofibromatosis was transmissible to healthy fish and suggested that an infectious agent such as a retrovirus could be the underlying cause ${ }^{3}$. A genetic etiology was also proposed ${ }^{4}$.

Researchers later pursued other animal models for neurofibromatosis, as technological advances enabled new techniques. Experimental mutagenesis of rodents and rabbits led to the development of tumors similar to those associated with neurofibromatosis ${ }^{5}$. Genetic engineers generated transgenic mice carrying a retrovirus, some of which developed multiple tumor phenotypes that resembled neurofibromatosis ${ }^{6}$. Jacks et al. used gene targeting to create a mouse model of neurofibromatosis, but the knockout mice did not develop neurofibromas ${ }^{7}$. Meanwhile, Sartin et al. reported the spontaneous development of multiple cutaneous neurofibromas in Holstein dairy cattle ${ }^{8}$. These cows also presented with intraocular lesions, reminiscent of iris hamartomas in human neurofibromatosis. Sartin et al. suggested that the cattle could serve as a useful animal model for neurofibromatosis, particularly if a specific NF1 mutation could be identified in the affected cows.

These results led to the suggestion that models of many human diseases could not be easily created, despite the existence of powerful new techniques, and that naturally occurring models would continue to be valuable for disease studies ${ }^{5}$. Hence, the bicolor damselfish serves as a case study not only for neurofibromatosis but also for the scientific process of animal model development.

1. Schmale, M.C., Hensley, G.T. \& Udey, L.R. Multiple schwannomas in the bicolor damselfish, Pomacentrus partitus: a possible model of von Recklinghausen neurofibromatosis. Am. J. Pathol. 112, 238-241 (1983).

2. Schlumberger, H.G. Nerve sheath tumors in an isolated goldfish population. Cancer Res. 12, 890-899 (1952).

3. Schmale, M.C. \& Hensley, G.T. Transmissibility of a neurofibromatosis-like disease in bicolor damselfish. Cancer Res. 48, 3828-3833 (1988).

4. Lacson, J.M., Riccardi, V.M. \& Morizot, D.C. Possible genetic etiology of damselfish neurofibromatosis: genetic differentiation of bicolor damselfish (Pomacentrus partitus) populations. Neurofibromatosis 1, 253-259 (1988).

5. Riccardi, V.M., Womack, J.E. \& Jacks, T. Neurofibromatosis and related tumors: natural occurrence and animal models. Am. J. Pathol. 145, 994-1000 (1994).

6. Hinrichs, S.H., Nerenberg, M., Reynolds, R.K., Khoury, G. \& Jay, G. A transgenic mouse model for human neurofibromatosis. Science 237, 1340-1343 (1987).

7. Jacks, T. et al. Tumour predisposition in mice heterozygous for a targeted mutation in Nf1. Nat. Genet. 7, 353-361 (1994).

8. Sartin, E.A. et al. Characterization of naturally occurring cutaneous neurofibromas in Holstein cattle: a disorder resembling neurofibromatosis type 1 in man. Am. J. Pathol. 145, 1168-1174 (1994). 